\title{
"Um resumo do Brasil": diferença e historicidade na construção do rural no Paraná
}

\author{
Beatriz Anselmo Olinto ${ }^{1 *}$ \\ ${ }^{1}$ Universidade Estadual do Centro-Oeste do Paraná, Guarapuava/PR - Brasil
}

Marcos Nestor Stein ${ }^{2 * *}$

${ }^{2}$ Universidade Estadual do Oeste do Paraná - Marechal Cândido Rondon, PR - Brasil

\section{RESUMO}

O presente artigo aborda discursos sobre o rural no estado do Paraná, em meados do século XX. Serão analisados os principais eixos performativos dos discursos sobre as gentes e as terras desse estado, elaborados em artigos, ensaios e discursos de Bento Munhoz da Rocha Neto, entre 1951 e 1955, quando governou o estado, bem como na obra Dois repórteres no Paraná, publicada sob os auspícios de seu governo, em 1953. O foco é problematizar as subjetivaçôes organizadas por tal discursividade, as quais criaram e (des)qualificaram personagens, articulando-os aos condicionantes externos - meio, clima, heranças culturais, psicologia - de forma a limitar a ação desses sujeitos e capacitá-los, ou não, em um processo de construção da noção de propriedade e proprietários naquele estado. Tais eixos narrativos serão compreendidos como acontecimentos discursivos que se articulam dentro de narrativas historicizadas, ou seja, narrativas que compôem regimes de historicidades. O objetivo principal é conhecer como os projetos de (re)ocupação de grandes áreas do território paranaense estavam ligados a um projeto de futuro nacional e à construção de um Brasil diferente. Palavras-chave: história rural; historicidade; identificaçôes; regióes.

DOI: http://dx.doi.org/10.1590/2237-101X02004210.

Artigo recebido em 20 de junho de 2018 e aceito para publicação em 14 de fevereiro de 2019.

* Professora da Universidade Estadual do Centro Oeste do Paraná / Departamento de História, campus Guarapuava/PA - Brasil. E-mail: biaolinto@hotmail.com. ORCID: https://orcid.org/0000-0002-6520-0711.

** Professor da Universidade Estadual do Oeste do Paraná / Colegiado de História, campus Marechal Cândido Rondon/PR - Brasil. E-mail: mancha36@hotmail.com. ORCID: https://orcid.org/0000-0002-26230686.

O artigo é um dos resultados dos estágios de pós-doutorado desenvolvidos pelos autores na UFF. As pesquisas desenvolvidas nos estágios são vinculadas ao INCT Proprietas: História Social da Propriedade e Direitos de Acesso, coordenado pela professora Márcia Maria Menendes Motta. O presente trabalho foi realizado com apoio da Coordenação de Aperfeiçoamento de Pessoal de Nível Superior - Brasil (CAPES) - Código de Financiamento 001 . 


\title{
"A summary from Brazil": difference and historicity in rural construction in Paraná
}

\begin{abstract}
This article discusses rural discourses in the state of Paraná in the mid - 20th century. It analyses the main performative axes of discourses about the people and the land of this state elaborated in articles, essays and speeches of Bento Munhoz da Rocha, between 1951 and 1955, when he ruled the state, as well as in the work "Two reporters in Paraná", which was published under the auspices of his government in 1953. It aims to problematize the subjectivities organized by these discourses, which have created and (dis)qualified characters, articulating them to external constraints - environment, climate, cultural inheritance, psychology - in order to limit the action of these subjects and enabled them (or not) to participate in the construction of the notions of property and ownership in that state. Such narrative axes will be understood as discursive events that are articulated within historicized narratives, that is, narratives that compose regimes of historicities. The main objective is to know how the projects of (re)occupation of large areas of the territory of Paraná were linked to a project of national future and the construction of a different Brazil.
\end{abstract}

Keywords: rural history; historicity; identifications; regions.

\section{"Un resumen de Brasil": diferencia e historicidad en la construcción de lo rural en Paraná}

\section{RESUMEN}

El presente artículo aborda discursos sobre lo rural en el estado de Paraná, para mediados del siglo XX. Serán analizados los principales ejes performativos de los discursos sobre las personas y las tierras de ese estado, elaborados en artículos, ensayos y discursos de Bento Munhoz da Rocha, entre 1951 y 1955, cuando gobernó el estado, bien como en la obra "Dos reporteros en Paraná" publicada sobre los auspicios de su gobierno, en 1953. El foco es problematizar las subjetividades organizadas por tal discursividad, las cuales crearon y (des) calificaron personajes, articulándolos a los condicionantes externos -medio, clima, herencias culturales, psicología- de forma a limitar la acción de esos sujetos y capacitarlos, o no, en un proceso de construcción de la noción de propiedad y propietarios en aquel estado. Tales ejes narrativos serán comprendidos como acontecimientos discursivos que se articulan dentro de narrativas historicizadas, o sea, narrativas que componen regímenes de historicidades. El objetivo principal es conocer cómo los proyectos de (re) ocupación de grandes áreas del territorio paranaense estaban ligadas a un proyecto de futuro nacional y a la construcción de un Brasil diferente.

Palabras clave: historia rural; historicidad; identificaciones; regiones. 


\section{Introdução}

Em 1955, em palestra sobre o papel do Paraná na economia nacional, o então ministro da Agricultura e ex-governador do Paraná, Bento Munhoz da Rocha Neto ${ }^{1}$ afirmava: "O Paraná é hoje, literalmente, um resumo do Brasil, quer pelo meio físico quer pelo elemento humano, síntese de todas as heranças" ${ }^{2}$. Bento Munhoz não estava analisando apenas o presente, ele percebia no Paraná um modelo para a compreensão do país, um modelo de narrativa sobre o seu passado e sobre o seu futuro.

Em sua gestão no governo do Paraná, entre 1951 e 1955, Bento Munhoz iniciou as obras do Centro Cívico ${ }^{3}$, entre as quais estão o Palácio Iguaçu, sede do governo, o Palácio da Justiça, a Biblioteca Pública do Paraná e o Teatro Guaíra. Também criou a Fundação de Assistência ao Trabalhador Rural e a Secretaria do Trabalho e Assistência Social, as Casas Rurais e a Companhia Paranaense de Energia Elétrica (Copel). Como ministro da Agricultura, criou, pelo decreto-lei de 23 de setembro de 1955, o Serviço Social Rural, órgão subordinado ao ministério que, além de prestar assistência social aos trabalhadores rurais, principalmente nos campos da educação e saúde, visava fomentar a economia das pequenas propriedades e incentivar a criação de cooperativas ou associaçôes rurais. ${ }^{4}$

Cabe também registrar que, naquele momento, a economia paranaense era eminentemente rural exportadora. No norte, o café, cultivado por migrantes oriundos, em sua maioria, de São Paulo, havia suplantado a erva-mate e a madeira como principal produto do estado. ${ }^{5}$ Além disso, o período é marcado pelo processo de colonização do sudoeste e oeste do estado por agricultores vindos, em maior número, de Santa Catarina e Rio Grande do Sul e pela implantação, com incentivo do governo, de colônias agrícolas formadas por imigrantes europeus, como foi o caso das colônias de Witmarsun, no município de Palmeira, Castrolanda, em Castro e Entre Rios, em Guarapuava. ${ }^{6}$

\footnotetext{
${ }^{1}$ Bento Munhoz da Rocha Neto nasceu em Paranaguá (PR), em 17 de dezembro de 1905, filho do político Caetano Munhoz da Rocha, governador do Paraná de 1920 a 1928, e de Olga Carneiro de Sousa Munhoz da Rocha. Engenheiro e professor da Universidade Federal do Paraná (UFPR), deputado constituinte em 1946, deputado federal entre 1946 e 1951, governador do Paraná, de 1951 a 1955, ministro da agricultura em 1955 e, novamente, deputado federal, de 1959 a 1963. Faleceu em 1973.

Disponível em: htpp://www.fgv.br/cpdoc/acervo/dicionarios/verbete-biografico/bento-munhoz-da-rocha-neto. Acesso em: 14 mai. 2018.

${ }^{2}$ ROCHA NETO, Bento Munhoz da. O Paraná: ensaios. Curitiba: Coleção Farol do Saber, 1995. p. 52.

${ }^{3}$ Para uma interessante reflexão envolvendo a construçáo do centro cívico e as comemoraçôes do centenário de emancipação do Paraná, ver: BAHLS, Aparecida Vaz da Silva. A busca de valores identitários: a memória histórica paranaense. Tese (Doutorado em História). Curitiba: UFPR, 2007.

${ }_{4}^{4}$ Disponível em: htpp://www.fgv.br/cpdoc/acervo/dicionarios/verbete-biografico/bento-munhoz-da-rocha-neto. Acesso em: 14 mai. 2018.

${ }^{5}$ OLIVEIRA, Semi Cavalcanti de. Ciclos Econômicos da Erva-mate e do Café. In: SCORTEGAGNA, Adalberto et al. (org.). Paraná espaço e memória: diversos olhares histórico-geográficos. Curitiba: Editora Bagozzi, 2005. p. 204-227.

${ }^{6}$ Sobre a colônia Witmarsun, ver: BALHANA Altiva P.; MACHADO Paulo P. (orgs.). Campos gerais: estruturas agrárias. Curitiba: UFPR, 1968. Para mais informaçóes sobre a colônia Castrolanda, ver: ELFES,
} 
A (re)ocupação de vastas áreas do território do estado se fez acompanhar por diversos conflitos armados envolvendo a posse e a propriedade da terra. Os exemplos mais emblemáticos ocorreram no Sudoeste, com a Revolta dos Colonos, ou Levante dos Posseiros, ${ }^{7}$ e, no extremo norte, onde ocorreu a Revolta do Porecatu, ou Guerra do Porecatu. ${ }^{8}$

Levando isso em consideração, o presente artigo lança um olhar sobre algumas narrativas buscando compreender as maneiras pelas quais experiências e expectativas dialogaram e compuseram uma historicidade, na qual se associava o desenvolvimento agrário do Paraná com o mundo rural do Brasil, em meados do século XX. O foco da análise são os textos produzidos por Bento Munhoz da Rocha Neto e pelos jornalistas Rubem Braga e Arnaldo P. D'Horta, os quais acompanharam o então governador em uma viagem pelo interior do estado no ano de 1952. Da viagem resultou a publicação do livro intitulado Dois repórteres no Paraná, em 1953, ${ }^{9}$ em funçâo das comemorações do centenário da emancipação política do estado do Paraná. Em relação aos escritos de Rocha Neto, além de um texto publicado por ocasião das referidas comemorações, selecionamos duas publicaçôes que reúnem uma considerável quantidade de textos por ele produzidos. A primeira intitula-se Discursos e conferências: $1951-1955^{10}$ e é constituída por 48 textos, mas não há informaçóes sobre a data da publicação da coletânea. A segunda intitula-se $O$ Paraná: ensaios e é formada por 11 textos. Essa última foi publicada em 1995 como um volume da coleçáo Farol do saber, financiada pela prefeitura de Curitiba. No mesmo período, o governo estadual de Jaime Lerner (1995-2003) organizou a coleçáo Um Brasil diferente, expressão cunhada, na década de 1950, pelo historiador e literato Wilson Martins para particularizar o estado do Paraná em relação ao Brasil.

A escolha desse conjunto de escritos justifica-se em função dos eixos aqui problematizados, pois que abordam temáticas recorrentes nas obras de Rocha Neto, a saber: o Paraná rural como regiáo estabelecida e delimitada a partir de sua história, as gentes que em seu território se fixaram, ou estavam se fixando, e as interpretaçôes sobre aspectos de sua natureza, especialmente o solo e o clima. Compreendemos que as palavras reorganizavam o viver social e político e forneciam novos sentidos aos acontecimentos entâo experienciados. Nessa perspectiva, acompanhamos as reflexóes de Maria Julieta Cordova acerca das ligaçôes entre a política, a história e o discurso identitário para Rocha Neto:

Albert. Campos gerais: estudo da colonização. Curitiba: Incra,1973. Acerca do processo de formação da colônia Entre Rios, ver: STEIN, Marcos N. O oitavo dia: produção de sentidos identitários na Colônia Entre Rios-PR (segunda metade do século XX). Guarapuava: Unicentro, 2011.

7 WACHOWICZ, Ruy C. Paraná, sudoeste: ocupação e colonização. Curitiba: Lítero-Técnica, 1985.

${ }^{8}$ PRIORI, Angelo. A Guerra de Porecatu. Revista Diálogos. DHI/PPH/UEM, v. 14, n. 2, p. 367-379, 2010.

${ }^{9}$ Para essa análise, utilizamos a 2a edição, de 2001.

${ }^{10}$ ROCHA NETO, Bento Munhoz da. Discursos e conferências: 1951-1955. Curitiba: Imprensa Oficial. s/d. 
[...] a política, para Bento, estava comprometida de forma eficaz, com o sentido simbólico, especialmente na reprodução de ideias sobre identidade do paranaense, que ainda que sempre em busca do progresso, não deveria nunca deixar de lembrar de seu passado e de sua história. ${ }^{11}$

Diante disso, levando-se também em consideração os limites de um artigo, serão abordados dois eixos performativos ${ }^{12}$ : as subjetivaçóes, que criam, qualificam e desqualificam sujeitos, em processos que constituem noçóes naturalizadas de proprietários (fazendeiros e colonos) e não proprietários (nordestinos, caboclos, negros e índios) das terras então (re) ocupadas; e os condicionantes externos, nos quais meio, biologia, heranças culturais, psicologia e/ou questóes sociais se apresentam como limitadores, ou determinantes, da ação dos sujeitos.

Serão analisadas as formas pelas quais tais performances se articulam dentro de narrativas historicizadas, ou seja, narrativas que articulam regimes de historicidades, compreendidos como: "maneiras de engrenar passado, presente e futuro ou de compor um misto das três categorias", ${ }^{13}$ tanto em relação ao estado quanto lançando expectativas em um horizonte nacional. Trata-se de uma historicidade que produz um conhecimento sobre o passado ao mesmo tempo em que projeta um futuro. Nas palavras de Koselleck:

Esperança e recordação, ou mais genericamente, expectativa e experiência - pois que a expectativa abarca mais que a esperança, e a experiência é mais profunda que a recordação são constitutivas, ao mesmo tempo, da história e de seu conhecimento, e certamente o fazem mostrando e produzindo a relação interna entre passado e futuro, hoje e amanhã. ${ }^{14}$

Ou seja, buscamos perceber como concepçóes de passado, presente e futuro são utilizadas para compor uma temporalidade com um sentido progressivo, ${ }^{15}$ envolvendo, especialmente, a posse da terra no Paraná por determinados grupos humanos. Cabe adiantar que

${ }^{11}$ CORDOVA, Maria Julieta W. O discurso regional autorizado de formação social e histórica paranaense. Sociologia \& Politica. I Seminário Nacional de Sociologia e Política. UFPR: 2009. Disponível em: https:// www.humanas.ufpr.br/site/evento/SociologiaPolitica/anais/gt6.htm, 2009. p. 5.

12 "O discurso regionalista é um discurso performativo, que tem em vista impor como legítima uma nova definiçáo das fronteiras e dar a conhecer e fazer reconhecer a região assim delimitada”. BOURDIEU, Pierre. O poder simbólico. Rio de Janeiro: Bertrand, 1989. p. 116.

${ }^{13}$ HARTOG, François. Regimes de historicidade: presentismo e experiências do tempo. Belo Horizonte: Autêntica, 2013. p. 11.

${ }^{14}$ KOSELLECK, Reinhart. Futuro passado: contribuição à semântica dos tempos históricos. Rio de Janeiro: Contraponto/ PUC-Rio, 2006. p. 308.

${ }^{15}$ Ainda segundo Koselleck, o século XVIII traz, junto com o conceito moderno de História (Geschichte), uma filosofia do progresso: “(...) o progresso descortina um futuro capaz de ultrapassar o espaço do tempo e da experiência tradicional, natural, prognosticável, o qual por força de sua dinâmica, provoca por sua vez novos prognósticos, transnaturais e de longo prazo." Ibidem, p. 36. Tais prognósticos alienados do campo de experiência tradicional, e com uma percepçáo acelerada de futuro próximo, podem ser acompanhados, também, nos textos analisados no presente artigo. 
esses eixos performativos dos discursos não se dão separadamente, pois que, nas fontes, se encontram mesclados, sobrepostos, constituindo determinados sentidos narrativos.

Por discursos, entendem-se a efetividade e a regularidade de uma fala, suas paráfrases e sua polissemia em um dado momento histórico, momento por ela mesma delimitado a partir do seu acontecimento. Porém, dentro desses discursos, serão problematizadas as construçóes narrativas, tanto memorialísticas, quanto historiográficas, geográficas e institucionais, enquanto espaços de sentido, os quais fornecem uma inteligibilidade para as experiências vividas, projetam desejos, estabilizam identidades e organizam noções de história.

A opção será uma variação de escala para a análise das fontes - sem seguir uma ordem cronológica dos escritos -, buscando as interaçóes entre o local e o geral, região e nação, suas exclusóes e sobreposiçóes, as quais permitem que se diga um Paraná para explicar um Brasil. Em outros termos, a hipótese que propomos para o debate, neste artigo, é a de que o estado em questão foi constituído como uma região não apenas delimitando uma especificidade para si e para as suas sub-regióes, mas sim projetando-o como um modelo para a nação.

Acompanhando as reflexões de Yves Lacoste sobre a Geografia Regional de tradição francesa, pode-se perceber como as regiōes são constituídas com individualidades, personalidades preexistentes, para as quais "o papel da geografia seria talhar sua fisionomia e mostrar os seus traços resultando de uma harmoniosa interação entre condiçóes naturais e heranças históricas muito antigas". $\mathrm{O}$ autor denomina essas formas narrativas de "geografismos", ou seja, metáforas que alçam porções do espaço terrestre à condição de forças políticas e de sujeitos da história, porém:

(...) esses malabarismos de estilo não são assim tão inocentes como podem parecer à primeira vista, pois eles permitem escamotear as diferenças e as contradiçóes entre os diversos grupos sociais que se encontram nesses lugares ou sobre esses territórios. E a razão pela qual esses geografismos são tão utilizados nos discursos patrióticos, quer se trate do Estado nação ou da região, que alguns consideram como mininaçóes ou como naçóes em potencial. ${ }^{17}$

Nesse sentido, voltando a Rocha Neto, pode-se compreender como a construção de uma historicidade para o Brasil passava pela composição de regióes, tipos humanos, problemas e temporalidades. As próximas páginas buscam lançar algumas reflexões sobre a construção dessa paisagem de complexidade.

\footnotetext{
${ }^{16}$ LACOSTE, Yves. A geografia: isso serve, em primeiro lugar, para fazer a guerra. p. 29. Disponível em: www.sabotagem.cjb.net. Acesso em: 13 nov. 2018.

${ }^{17}$ Ibidem, p. 31.
} 


\section{Os prisioneiros da temporalidade: sujeitos do presente-passado e do futuro-presente}

Refletir sobre a construção de uma determinada imagem do Paraná rural - incluindo as suas "gentes" que, como veremos mais adiante, são também classificadas a partir da sua suposta inserção em diferentes temporalidades - e os sentidos que envolviam o Brasil, pode contribuir no debate e na compreensão tanto das mudanças quanto das permanências das concepçôes e dos projetos sobre o rural na organizaçáo do referido estado e da naçáo brasileira.

Um exemplo da constituição desse tipo de imagem é o que podemos perceber no seguinte fragmento de um dos escritos de Bento Munhoz da Rocha Neto:

Paranaenses de todas as origens culturais se sentem igualmente paranaenses, julgamse progressivamente iguais aos outros de sua convivência diária, das suas ligaçóes, de sua solidariedade, de suas afinidades, à gente, enfim da sua regiáo brasileira [...] Ser paulista, paranaense, catarinense ou gaúcho, sentir-se preso ao seu meio, onde se situa o centro de todos os seus interesses, preocupaçôes e aspirações, é, para gente de poucas geraçóes do Brasil, o grande e verdadeiro caminho de inteira assimilação pela cultura nacional. ${ }^{18}$

Nesse fragmento do texto intitulado "Regionalismo" - aspecto que Rocha Neto julgava essencial para a compreensão do Brasil ${ }^{19}$-, podemos observar como ele definia os estados com sinônimos de regiôes, apagando outras diferenças internas a eles e, ao mesmo tempo, naturalizando-os no binômio regiáo-meio. Trata-se, assim, da construção de um quadro de tipos humanos - as gentes -, espaços geográficos e econômicos que caracterizavam o presente do estado e do Brasil. Ao final, Rocha Neto sinaliza para uma outra temporalidade, o futuro, quando as diferenças entre os habitantes dos estados brasileiros seriam apagadas por meio do processo - também naturalizado - de assimilação.

Percebe-se que a constituição de sujeitos e a delimitação das regiốes também estão presas às distintas temporalidades, o que implica a eleiçáo daqueles que adentrariam o futuro $\mathrm{e}$ dos que permaneceriam no passado e, portanto, desapareceriam nesse suposto processo de assimilação. Tal narrativa também pode ser acompanhada na sua mensagem apresentada à Assembleia Legislativa do Estado, em 1953. A mensagem integra a publicação oficial relativa ao $1^{\circ}$ centenário de emancipação política do Paraná. Além da apresentação de obras e serviços executados pelo governo em diversas áreas do estado, o discurso classificava e produzia uma ordem no processo de (re)ocupaçáo de seu território, processo que é nominado e

\footnotetext{
${ }^{18}$ ROCHA NETO, Bento Munhoz da. Discursos e conferências, op. cit. p. 217.

${ }^{19}$ Em suas palavras: "A simples extensão territorial do Brasil é uma condição de diversidades regionais. A imigração europeia, começada na primeira metade do século XIX, ainda mais as ampliou. E é pela própria região, que os brasileiros, novos pela cultura, são incorporados culturalmente à grande unidade nacional." ROCHA NETO, Bento Munhoz da. Discursos e conferências, op. cit, p. 217.
} 
adjetivado como "invasão benéfica que cobre o Paraná” ${ }^{20}$. Em que pese a positivação desse processo migratório - como indica a expressão supracitada - o discurso que segue possui um tom menos enaltecedor. Vejamos:

Sinto no Governo o reverso da nossa evolução trepidante e, mais ainda, os efeitos da rápida transformação do nosso estilo de atividade econômica. Testemunho o surgimento do desnível econômico, inédito até então no Paraná, terra clássica da pequena lavoura de subsistência, com a avalanche da onda cafeeira que traz riqueza, mas é acompanhada também por multidóes de desajustados e doentes. Percebe-se a miséria que acompanha o progresso. ${ }^{21}$

Na passagem acima, a miséria é vista como o acompanhamento inexorável do progresso cafeeiro e não como sua consequência. Nessa perspectiva, as pessoas não se tornariam desajustadas ou doentes pelo modelo de desenvolvimento econômico defendido pelo autor e sim pela velocidade das transformaçóes perpetradas por esse modelo. Embora Rocha Neto constitua o rural paranaense como um espaço de aceleradas mudanças que produziriam riqueza, há a permanência de um aspecto que define esse espaço: a carência, a pobreza de grande parte de sua população. ${ }^{22}$ Daí a necessidade de intervenção do Estado por meio da Fundação de Assistência ao Trabalhador Rural e das Casas Rurais. Outro elemento que chamou nossa atenção é que a denominação de tais mudanças como "evolução" - noção que inclui aprimoramento - é colocada em xeque pelo próprio autor ao apontar o "desnível” como algo novo, e que era trazido por ela, em oposição ao espaço de experiência agrícola anterior no estado. Nesse sentido, o desajustado seria também aquele que não estaria em sincronia com o novo tempo. Esse também seria um sujeito coletivo apresentado como externo ao Paraná, vindo do Brasil em uma "onda”, ou seja, um movimento causado pela própria mudança. A sobrevivência dessas pessoas naquele novo presente seria possível somente, segundo o autor, por meio da ação estatal.

Com esse panorama, Rocha Neto, em seguida, apresenta detalhes acerca das açóes que deveriam ser implementadas pela Fundação de Assistência ao Trabalhador sobre tal população, tais como a verificação das suas condiçóes sanitárias e educacionais. Assim, essas pessoas recém-chegadas eram percebidas como miseráveis em recursos, saúde e conheci-

${ }^{20}$ ROCHA NETO, Bento Munhoz da. Mensagem apresentada à Assembleia Legislativa do Estado. In: PARANÁ. $1^{\circ}$ Centenário da Emancipação Política do Paraná (1853-1953). Curitiba: Edição do Governo do Paraná. 1953. p. 12.

${ }^{21}$ Idem.

${ }^{22}$ Atualmente, essa perspectiva sobre o rural é objeto de diversas críticas. Um dos autores que critica essa visão do rural é Ricardo Abramovay. Em suas palavras: "Há um vício de raciocínio na maneira como se definem as áreas rurais no Brasil, que contribui decisivamente para que sejam assimiladas automaticamente a atraso, carência de serviços e falta de cidadania”. In: ABRAMOVAY, Ricardo. Funçôes e medidas da ruralidade no desenvolvimento contemporâneo. Rio de Janeiro: IPEA, 2000. p. 2. Disponível em: http://ipea.gov.br/agencia/ images/stories/PDFs/TDs/td_0702.pdf. Acesso em: 15 nov. 2018. 
mentos. A elas seriam oferecidos "ensinamentos que vão da enfermagem à horticultura". ${ }^{23}$ Em outros termos, as açóes do Estado deveriam focar em uma educação que congregasse aspectos sanitários, cujo objetivo seria a superação da condição perigosa de doentes, e a instrução acerca do cultivo de hortaliças, um conhecimento utilitário. Tratava-se, portanto, da constituição de seres saudáveis e produtivos, os quais deixariam de ser um problema ao terem um lugar hierarquicamente definido no presente e no futuro. Para essa "multidão", deve-se ressaltar que o tema da propriedade da terra não era abordado em nenhum momento e os projetos estatais não os enxergavam como sujeitos potencialmente proprietários das tais lavouras de café ou de gado. A educação rural era apresentada como uma característica desse Paraná sujeito e modelo do desenvolvimento nacional. Sobre os projetos de educação rural desenvolvidos nos outros estados, inclusive no vizinho e cafeicultor São Paulo, ${ }^{24}$ nada é dito. Silenciamento que funciona como estratégia discursiva para a construção do horizonte de progresso como uma excepcionalidade identitária para o Paraná.

A imagem de uma população carente, configurada pela sua miséria, é logo substituída pelo seu contraponto: a população do centro-sul do Paraná. Tal região é classificada como "zona da lavoura de subsistência", onde vive o "lavrador de origem europeia recente" e onde "raramente existem trabalhadores rurais assalariados". Para essa região e essa população, a intervenção do governo não é colocada de imediato, pois esse lavrador seria "portador de outras heranças" e, portanto, “a técnica deverá ser diferente, e a experiência indicará os caminhos a seguir ${ }^{25}$. Ou seja, diferentemente das gentes pobres das áreas de produção de café, caracterizadas como "desajustados", narrados anteriormente, para os imigrantes europeus do centro-sul paranaense, o passado não é o grilhão que os impede de prosperar, mas, ao contrário, constitui o guia para o futuro. Salienta-se aqui como a opção por uma forma narrativa apoiada em conhecimentos geográficos sobre as sub-regióes paranaenses possibilita enquadrar as questóes levantadas pelo autor em quadros físicos, como se fossem dados naturais e não humanos.

Na página seguinte, o olhar volta a ser dirigido para o norte, para Maringá e Peabiru. O Estado é novamente apresentado como instrumento cuja função é prestar assistência "[...] mais direta aos nacionais, principalmente aos nordestinos que, mais uma vez batidos pela inclemência das secas, procuram o Paraná em ondas sucessivas”. ${ }^{26}$. Ou seja, trata-se de uma imagem em que os nordestinos estão presos - e, portanto, estão constituídos por uma determinada temporalidade - a um pretérito e a uma região, que também é constituída

${ }^{23}$ ROCHA NETO, Bento Munhoz da. Mensagem apresentada à ...., op. cit, p. 12.

${ }^{24}$ Destaca-se, aqui, o Congresso Agrícola de 1878, em São Paulo, que estipulou a "educação para o trabalho através da criação de escolas agrícolas" como uma de suas reinvindicações, bem como a fundação do Instituto Agronômico de Campinas e da Escola Superior de Agricultura Luís de Queiroz, em Piracicaba, ao início do século XX. Ver: NAXARA, Márcia R. C. Estrangeiro na sua própria terra: representaçóes do brasileiro 1870/1920. São Paulo: Annablume, 1998. p. 53 e 68.

${ }^{25}$ Idem.

${ }^{26}$ Ibidem, p. 13. 
como vinculada a um passado, pois é adjetivada como "velhos lugares em que viveram seus ancestrais" 27 . Logo em seguida, o autor enaltece o "dever de brasilidade e humanidade do Paraná", ao aliviar o sofrimento "de tantos brasileiros" - sem, no entanto, mais uma vez, constituí-los como sujeitos para o futuro.

Na sequência, a narrativa transforma-se em números que procuram quantificar a produçâo de café do estado - 5 milhôes de sacas, que correspondem a $30 \%$ da produção nacional - e a riqueza proveniente de sua exportação: 300 milhóes de dólares. Aqui, o Paraná novamente é instituído como uma espécie de sujeito que desempenha um papel no presente que, concomitantemente, já se encontra projetado em um futuro que envolve o Brasil. É o que Rocha Neto sintetiza por meio da seguinte frase: "Não me canso de falar sobre a missão que ao Paraná cabe realizar na evolução da economia cafeeira nacional”. ${ }^{28}$ Para o autor, o Paraná teria uma missão para com a nação, uma perspectiva de apontar o seu futuro, sua evoluçáo, o que nos lembra novamente das reflexôes de Lacoste, para quem "Os geografismos proliferam nos discursos políticos". ${ }^{29}$

Em seguida, a narrativa traz uma advertência acerca dos perigos que podem acometer esse processo em que o leitmotiv é a produção de café:

Não pode ser uma fatalidade o nomadismo da cultura do café, e se o Paraná está ainda no seu início da sua capacidade de produção, é preciso prever e evitar que se venham a repetir aqui os mesmos erros que tem acompanhado a onda verde. É preciso evitar que à prosperidade trazida pelo café suceda o deserto ou então outro gênero de cultura, desorganizando sucessivamente os fundamentos da economia brasileira. ${ }^{30}$

Esse perigo do Paraná, no futuro, tornar-se o presente das regiôes cafeeiras em decadência, é logo afastado ao indicar a açẫo de sujeitos positivados, a saber: "os fazendeiros, aqueles que detêm a consciência que é mais [...] conveniente conservar do que recuperar o solo". ${ }^{31}$ Já os "pequenos lavradores" seriam assistidos pelo Estado por meio das "Casas Rurais", que venderiam a preço de custo vacinas, sementes e máquinas.

O próximo aspecto abordado na obra envolve a instalação de imigrantes europeus. Vejamos como esse cenário, localizado em Guarapuava e em Castro, é constituído:

O Estado tem facilitado a imigração estrangeira para as zonas paranaenses que, pelo seu clima, mais se prestam à colonizaçáo europeia. O êxito da colônia de Entre Rios, com a sua promissora cultura de trigo, está destinado a revolucionar os velhos métodos agronômicos conservados em

\footnotetext{
${ }^{27}$ Idem.

${ }^{28}$ Idem.

${ }^{29}$ LACOSTE, Yves. A geografia, op. cit, p. 31.

${ }^{30}$ Idem.

${ }^{31}$ Idem.
} 
grandes áreas do estado, valorizando-as decisivamente. Além de Castrolanda, onde holandeses se estão localizando, o estado estuda com os órgãos federais a localização de grandes correntes de lavradores europeus em zonas de condiçôes semelhantes às de Guarapuava. ${ }^{32}$

Portanto, o território paranaense é loteado em função de seu clima, perspectiva de produção agrícola - no caso acima, o trigo - e em função da população constituída como ideal para ocupá-lo. Esses três aspectos somados desaguavam, para o autor, em um futuro não muito distante, em que uma das características fundamentais seria a valorização das terras.

Após isso, a fala de Rocha Neto retorna a dissertar sobre os nacionais. A metáfora envolve, uma vez mais, uma noção climática: a seca, é em oposição a essa que o estado se constitui: "O Paraná é buscado como um oásis, para onde se dirigem os homens insatisfeitos da instabilidade econômica nacional". ${ }^{33}$ Ao não apresentar detalhes sobre essa instabilidade no âmbito nacional, e nem o porquê do Paraná não ser afetado por ela, a narrativa produz uma paradoxal imagem em que o estado é inserido simultaneamente fora do Brasil - pois não padece de seus problemas econômicos - e no seu interior, como uma das unidades da federação. Nesse sentido, o Paraná seria como um oásis cercado pelo deserto da crise econômica, para onde os sedentos por terra, riqueza e futuro se deslocavam.

A importância de tal movimento migratório é, na sequência, reforçada com a apresentação de dados sobre o crescimento demográfico do estado, de 126.722, em 1872, para 2.115,547, em 1950. Semelhante comparação é feita em relação ao orçamento. ${ }^{34}$ Nesse caso, lançava-se mão de números não apenas para informar as diferenças entre a quantidade de pessoas e de recursos dos primeiros anos da província e à época das comemorações de seu centenário, mas também para estabelecer uma espécie de continuidade e de aceleração desse crescimento. É um quadro homogeneizante que não apresenta a distinção, encontrada nos parágrafos anteriores, entre aqueles para quem o futuro reserva um lugar ao sol - como, por exemplo, os fazendeiros proprietários de terras - e para aqueles que permaneciam presos ao passado.

Entretanto, o quadro que estabelecia os sujeitos do passado, do presente e do futuro, a partir da posse e propriedade da terra, é ampliado em outra publicação comemorativa ao centenário do Paraná, produzida quando os repórteres Rubem Braga e Arnaldo P. D’Horta acompanharam o então governador do Paraná em viagem pelo estado, em 1952. Rubem Braga (1913-1990), escritor e jornalista, ganhou notoriedade como cronista de jornais e revistas de grande circulação no país e como correspondente de guerra do Diário Carioca junto às tropas da Força Expedicionária Brasileira na Itália, durante a Segunda Guerra Mundial 35 .

\footnotetext{
${ }^{32}$ Ibidem, p. 14.

33 Idem.

34 “(...) de 176.4000\$000, de 1854 a 1855, para Cr\$1.649.644.333,70 em 1953.” Idem.

${ }^{35}$ Para uma aprofundada análise das crônicas de guerra na Itália escritas por Braga, que envolvem história, literatura e jornalismo, ver: MELO, Mariani Carolina de Souza. A crônica vai à guerra: Rubem Braga e os escritos do front. Dissertação (Mestrado em Teoria Literária). Uberlândia: UFU, 2016.
} 
Entre 1961 e 1963, atuou como embaixador em Marrocos. ${ }^{36}$ Arnaldo Pedroso D'Horta (1914 - 1973) foi desenhista, pintor, crítico de arte, professor e jornalista. Como jornalista, atuou em jornais como a Folha da Manhã e O Estado de S. Paulo, mas foi o desenho e a gravura que lhe deram mais notoriedade. ${ }^{37}$

O livro Dois repórteres no Paraná é constituído por sete capítulos. Cada capítulo é composto por um texto de Braga e outro de D’Horta. O primeiro apresenta informaçóes e impressóes de ambos ao chegarem em Curitiba. O segundo capítulo intitula-se "De Curitiba a Porecatu”, e reúne os textos “As Terras Devolutas”, assinado por D’Horta, e "Terras”, de Braga. Provavelmente, a escolha de Porecatu, situado no extremo norte do Paraná, para ser a primeira localidade a ser visitada, deve-se ao fato de ali ter sido palco de um grave conflito agrário, de repercussão nacional, também denominado "Guerra de Porecatu", ocorrido no final da década de 1940 e início dos anos de 1950. O conflito envolveu posseiros, jagunços, grileiros, governo do Paraná e dirigentes do partido comunista - que atuaram na organização da resistência armada e das ligas camponesas na região. A resistência armada dos posseiros foi sufocada com a ação da polícia militar do Paraná e de agentes das Delegacias Especializadas de Ordem Política e Social (DOPS). ${ }^{38}$

Começaremos nossa análise do capítulo sobre Porecatu pelo texto de Braga. Percebe-se um discurso que constrói uma ordem temporal para a questão de quem seria o dono das terras por aquelas bandas: "No princípio, as terras eram todas de Deus. Depois um governo deu uma imensa concessão neste norte do Paraná. [...] Então as terras passaram a ser todas do Diabo". ${ }^{39} \mathrm{Na}$ passagem, a propriedade da terra é posta em uma temporalidade sagrada, entre Deus e o Diabo. O princípio e o fim aparecem mediados pela ação do governo em concedê-la a outrem. Não há propriedade antes, e o presente é do Diabo, visto como o motor dos conflitos deflagrados no norte do Paraná no período. O nascimento da propriedade é, assim, retirado da historicidade humana e atribuído a figuras metafísicas.

Em relação aos conflitos agrários, os autores tentam explicar o de Porecatu ${ }^{40}$ diminuindo a influência de comunistas e reafirmando a naturalidade da propriedade privada, assim:

Falou-se muito de comunismo no norte do Paraná, e isso por causa dos acontecimentos de Porecatu [...]. Muita gente chegou a pensar que o comunismo no Brasil tinha finalmente se

\footnotetext{
${ }^{36}$ Disponível em: https://www.ebiografia.com/rubem_braga/. Acesso em: 20 nov. 2017.

37 Disponível em: http://enciclopedia.itaucultural.org.br/pessoa9760/arnaldo-pedroso-dhorta. Acesso em: 20 nov. 2017.

${ }^{38}$ PRIORI, Angelo. A Guerra de Porecatu, op. cit.

${ }^{39}$ BRAGA, Rubem; D’HORTA, Arnaldo. Dois repórteres no Paraná. 2 ed. Curitiba: Imprensa Oficial do Paraná, 2001, p. 23.

${ }^{40}$ Para mais informaçôes, ver: PRIORI, Angelo et al. História do Paraná: séculos XIX e XX [online]. Maringá: Eduem, 2012. p. 129-41. Disponível em: http://books.scielo.org/id/k4vrh/pdf/priori-9788576285878-11. pdf. Acesso em: 13 nov. 2018.
} 
infiltrado no campo e se organizado entre os camponeses, para usar a linguagem sua predileta. Minha impressão [...], o comunismo continua a ser um fenômeno urbano. ${ }^{41}$

Nesse sentido, depois de afastada a ideia de comunismo no mundo rural, define-se que seria a falta de limites entre as propriedades e a revenda de terras para terceiros à revelia de vendas anteriores, que teriam causado o conflito, a saber:

Os distúrbios que ocorreram em Porecatu tiveram como causa principal o distúrbio assim produzido por autoridades inescrupulosas na situação de grande número de pessoas com interesse nas terras requeridas, ou que já as possuíam como posseiros. ${ }^{42}$

Uma vez trocado o governo, o problema estaria resolvido, pelo menos na visão de D’Horta. Em consonância, Braga afirma no capítulo denominado "Materialismo", que as pessoas chamadas pelo autor de "pioneiros" seriam "materialistas" demais para serem "comunistas". O que parece contraditório à primeira vista, é logo compreendido pela narrativa urdida pelo autor da seguinte forma: ser "materialista", para ele, consistia em objetivar, por meio de seu trabalho, apenas a obtenção de mais "dinheiro". Vejamos:

Aqui nessas terras, onde só se fala de trabalho e de dinheiro, a linguagem adotada é uma linguagem de negócio: 'não compensa'. O comunismo é apresentado como um negócio que não interessa, materialmente: um atraso de vida. ${ }^{43}$

Nessa passagem, pode se perceber que os pioneiros de Braga não são todas as pessoas que habitavam aquela região, mas sim, e apenas, os que empreendem atividades capitalistas, entendidas pelo autor como aquilo que criaria o progresso. Dicotomicamente, o comunismo é associado ao atraso, a algo do passado, já superado. ${ }^{44}$

Para os dois repórteres e seus olhares treinados para filtrar o mundo pela lente dicotômica do progresso e do atraso, os conflitos de terra apresentam-se como um desafio narrativo. Como explicar a grilagem empreendida pelo governo Lupion? Braga faz uso de termos morais como "orgia", "barafunda", que teriam sido promovidas em "quartos de hotel" por funcionários, intermediários e "magnatas das terras devolutas". ${ }^{45}$ Assim, a grilagem não era

\footnotetext{
${ }^{41}$ BRAGA, Rubem; D’HORTA, Arnaldo. Dois repórteres no Paraná, op. cit., p. 35.

${ }^{42}$ Ibidem, p. 20.

${ }^{43}$ Ibidem, p. 36-37.

${ }^{44}$ Uma interessante análise do discurso que envolve as categorias pioneirismo e comunismo foi realizada por José Rollo Gonçalves. GONÇALVES, José Henrique R. A mística do pioneirismo, antídoto contra o socialismo: Bento Munhoz da Rocha Neto, a reforma agrária e o Norte do Paraná dos anos 50 e 60. Revista História Regional, v. 2, n. 1. Ponta Grossa: UEPG, 1997.

${ }^{45}$ BRAGA, Rubem; D’HORTA, Arnaldo. Dois repórteres no Paraná, op. cit, p. 23 e 24.
} 
jamais compreendida como uma dinâmica perene da reocupação territorial brasileira ${ }^{46}$, mas como um ambiente de exceção causado pelo desgoverno de um político específico e solucionada com a chegada de Bento Munhoz da Rocha ao governo do estado, quando "conseguiu descascar o mais horrível abacaxi que recebeu de herança”. Diz o Governador em discurso: "Cuidei de defender os pobres porque os ricos, esses sabem se defender muito bem" ${ }^{\text {" Cabe }}$ aqui lembrar que, findo o governo de Munhoz da Rocha, Moisés Lupion foi reeleito como governador do Paraná. ${ }^{48}$

Percebe-se um procedimento de repetição na ordenação dos discursos analisados. Não são discursos somente ditos, mas constantemente repetidos e com reapariçóes solenes e comentários. É o que ressalta Braga: "Como o Sr. Bento Munhoz não cansa de repetir (...)”. 49 Tal afirmação sugere que não se queria nenhuma novidade no que era dito, era preciso ordenar e controlar os acontecimentos, discursivos ou não.

Ao analisarmos a estrutura do livro e como os sujeitos proprietários e não proprietários são nele constituídos, percebe-se que as distinções são compostas e tramadas em relações com as diferentes temporalidades. É o que podemos ler no seguinte fragmento do texto sobre Porecatu:

Os mais ricos lavradores paulistas que emigraram para o Paraná estão evitando reproduzir aqui os erros da lavoura cafeeira paulista. Eles aprenderam que é bom negócio adubar o cafezal e protegê-lo contra a erosão. Para ajudar os novos cafeicultores a fazer o mesmo, o governo instalará, este mês, uma série de Casas Rurais. A marcha gloriosa e insensata dos batalhóes

\footnotetext{
${ }^{46}$ Acerca da grilagem, Márcia Motta afirma que: “1) (...) a grilagem não é recente, constitui-se, pois, num processo histórico e secular de ocupação ilegal; 2) (...) grilar não é uma prática isolada, mas tem a ver com os esforços dos senhores e possuidores de terra em expandir suas propriedades ad infinitun e 3) a grilagem não é somente um crime cometido contra o verdadeiro proprietário (seja um indivíduo, no caso de terras particulares invadidas, seja em áreas pertencentes ao Estado, no caso mais frequente de invasão de terras devolutas), mais é um crime cometido contra a nação.” A grilagem como legado. Disponível em: http://www.direito.mppr. mp.br/arquivos/File/Politica_Agraria/7MottaAGrilagemcomoLegado.pdf.

Acesso em: $04 \mathrm{dez} .2017$.

${ }^{47}$ BRAGA, Rubem; D’HORTA, Arnaldo. Dois repórteres no Paraná, op. cit., p. 25.

${ }^{48}$ Em seu primeiro mandato (1947-1951) como governador do Paraná, a administração de Lupion "[...] foi marcada pelo agravamento da luta armada entre posseiros e grileiros, que disputavam a posse das terras do norte do estado. Nessa época, Lupion fundou a Clevelândia Industrial e Territorial (Citla), empresa voltada para a colonização e a exploração madeireira que se envolveu nos anos seguintes em graves conflitos sociais no campo paranaense". Em seu segundo mandato como governador (1956-1961), "agravaram-se os conflitos agrários no Paraná, pois os lavradores se recusavam a deixar as terras em que trabalhavam, organizando a resistência armada aos pistoleiros contratados por algumas empresas. Essa luta resultou em sucessivos levantes em municípios da região sudoeste do estado, como Francisco Beltrão, Pato Branco, Santo Antônio e Capanema. $\mathrm{Na}$ condiçáo de proprietário da Citla, Lupion foi envolvido diretamente nesses conflitos, sendo acusado pela imprensa e por parlamentares oposicionistas de utilizar a Força Pública do estado em auxílio à açáo violenta das empresas imobiliárias". Disponível em: http://www.fgv.br/cpdoc/acervo/dicionarios/ verbete-biografico/moises-lupion-de-troya.

${ }^{49}$ BRAGA, Rubem; D’HORTA, Arnaldo. Dois repórteres no Paraná, op. cit., p. 22.
} 
verdes, em busca de terras novas deve parar: estas aqui, do setentrião paranaense, são as últimas do Brasil a poder produzir o café com um alto rendimento. A um Paraná que sempre viveu de mate e madeira o sr. Bento Munhoz da Rocha não se cansa de repetir que é preciso ter consciência de que o estado está vivendo o seu ciclo do café. ${ }^{50}$

Fazendeiros ricos vindos de São Paulo possuiriam um conhecimento advindo de fracassos anteriores; a experiência seria pedagógica para esses e impediria que repetissem os mesmos erros do passado no futuro. Diferente dos primeiros, as pessoas que eram mais novas no cultivo do café necessitariam de auxílio do governo para poderem ter êxito em sua lavoura. O conhecimento não estaria com eles, não haveria experiência pedagógica no seu passado, o conhecimento lhes era externo e deveria ser transmitido através dos projetos do governo estadual. O café havia encontrado o seu lugar final, o "setentriáo paranaense", visto quase como um ponto de chegada, como um destino para aquele cultivo, o que só se torna possível através da construçấo de mais um geografismo discursivo por parte do autor.

\section{Agricultores, caboclos, favelados e os condicionantes para o futuro}

De forma semelhante ao que se pode observar no fragmento sobre Porecatu, citado na seção anterior deste artigo, o quadro de conflito e desordem é substituído na narrativa quando os dois repórteres abordam a fixação de imigrantes suábios do Danúbio, em Guarapuava. Agora, eles teciam - através da instituição de uma relação entre passado, presente e futuro interna ao discurso - uma imagem de esperança apaziguadora como o horizonte de expectativa. Vejamos um fragmento desse discurso:

São alemães, de famílias que estavam radicadas há 200 anos na Iugoslávia, e que deixaram esse país em 1944, quando Tito subiu ao poder, para se refugiarem na Áustria. Organizaram uma cooperativa, e graças a empréstimos conseguidos de uma sociedade suíça de ajuda a refugiados de guerra, puderam aparelhar-se para vir instalar-se no Brasil. São todos agricultores - mas agricultores europeus, e não faltam em seu meio, os mecânicos, os eletricistas, os agrônomos. ${ }^{51}$

A narrativa constrói sentido, unifica o que é plural, tece coerências e apresenta um trajeto. Com isso, a diversidade étnica do grupo era apagada, tornam-se alemáes; seu apoio aos nazistas durante a Segunda Guerra era silenciado, foi Tito quem os expulsou; a negativa da Alemanha em permitir a entrada desses refugiados em seu território era esquecida, eles

\footnotetext{
${ }^{50}$ Ibidem, p. 52.

${ }^{51}$ BRAGA, Rubem; D’HORTA, Arnaldo. Dois repórteres no Paraná, op. cit., p. 73-74. 
apenas ficaram na Áustria. ${ }^{52} \mathrm{O}$ apoio do governo do Paraná para a vinda também sofria o mesmo processo de apagamento, afinal, eram europeus, eles organizariam a cooperativa autonomamente - ao contrário dos agricultores nacionais que necessitavam de apoio dos projetos do governo como as Casas Rurais, mencionadas anteriormente.

O mais importante para as reflexôes aqui propostas é a definição dos imigrantes como agricultores, pois que os autores estavam cientes das representaçôes que envolviam essa profissão no Brasil - onde rural era ligado a noçôes de atraso, arcaísmo e/ou degeneraçãa ${ }^{53}$-, por isso, justificavam a diferença desses agricultores recém-chegados: eram "europeus", o que acarretava, no texto, um arrolar de outras carreiras profissionais complementares e com maior status social nas terras tupiniquins - "mecânicos, eletricistas, agrônomos".

O texto continua reafirmando que a imigração foi custeada pelos próprios colonos, silenciando sobre a indenização dada pelo governo do Paraná aos fazendeiros desapropriados - indenização em dinheiro e terras ao Noroeste do estado. ${ }^{54}$ Ao qualificar positivamente esses imigrantes, construía-se, também, uma dualidade com a população brasileira, como pode se observar a seguir:

Eles trouxeram seu capital, suas máquinas, sua técnica e seu rude apetite de trabalho. Esse ano plantaram trigo mais cedo, e os trigais hão de madurar louros como as tranças de suas mulheres. Que sejam felizes, esses homens que produzem paz. Mas haja também no Brasil quem possa organizar 500 famílias brasileiras em cinco aldeias brancas - 500 famílias de gente da roça que nossa imprevidência e nosso desprezo deixam formar não essas aldeias brancas que se enxergam de longe, na imensidão dos campos, e sim mais uma súbita, sórdida e negra favela na perambeira de qualquer morro do Rio de Janeiro... ${ }^{55}$

O texto, assinado por Rubem Braga, articula, na passagem acima, preconceitos machistas e racistas comuns à elite intelectual brasileira em meados do século XX. Para o autor, os europeus não traziam só conhecimentos, eles teriam "apetite" por trabalho, mesmo que "rude", mas também branqueariam as paisagens e populaçôes brasileiras com o entendimen-

\footnotetext{
52 Sobre a vinda dos suábios para o Brasil, ver: STEIN, Marcos N. O oitavo dia: produção de sentidos identitários na Colônia Entre Rios-PR (segunda metade do século XX). Guarapuava: Unicentro, 2011.

${ }^{53}$ Sobre essas interpretaçóes do rural presentes na historiografia brasileira de esquerda no período, acompanhamos as reflexôes de Márcia Motta que, ao analisar a questão da escravidão em obra de Caio Prado Jr., destaca o seguinte: "A noção de degeneração, comum a muitos autores do período, corresponsabiliza o escravo pelo seu destino. As classes escravizadas, mal preparadas, tornar-se-iam um 'corpo estranho' na sociedade que ajudaram a construir por sua força e sua degeneração se espraiem por outras categorias de pobres livres. Há uma impossibilidade histórica para a existência digna daqueles homens." MOTTA, Márcia M. M. O rural à La gauche: campesinato e latifúndio nas interpretações de esquerda (1955-1996). Niterói: UFF, 2014. p. 99. Encontraremos paráfrases de tais interpretaçôes nas obras aqui analisadas.

${ }^{54}$ STEIN, Marcos N. O oitavo dia: produção de sentidos identitários na Colônia Entre Rios - PR (segunda metade do século XX). Guarapuava: Unicentro, 2011.

${ }^{55}$ BRAGA, Rubem; D’HORTA, Arnaldo. Dois repórteres no Paraná, op. cit., p. 78.
} 
to simultâneo - uma sinédoque - que ligava no texto os trigais às supostas louras tranças das mulheres imigrantes, dando um efeito pitoresco e tranquilizador como um sentido para essa imigração. Com essa forma, o autor produzia a paz que esperavam que os recém-chegados produzissem, mesmo se tratando de pessoas deslocadas por uma guerra mundial, na qual tomaram partido. Os homens trabalhadores plantariam trigo e, simbolicamente, clareariam os campos e as futuras gerações, pois que as mulheres eram ali metaforizadas pelo vegetal, tornando ambos objetos da açáo masculina (re)produtiva em um horizonte de expectativa planificado de branqueamento nacional. A imigração no Paraná era, assim, um modelo para um futuro brasileiro desejado pelos autores da obra.

Tal desejo de futuro, esse futuro-presente, era construído em confessa oposição ao Brasil daquele momento. O presente nacional era entendido como marcado pelo passado escravista, compreendido pejorativamente como "favelado" e "imprevidente", ou seja, incapaz de ele mesmo prover, prever e projetar perspectivas para o futuro. Tal caracterização nacional foi observada também no trabalho de Cordova, que analisou os discursos regionalistas de Bento Munhoz da Rocha Neto. Segundo ela:

Para Bento, a mancha loira do Brasil constituía-se num contraponto teórico do que até então se produzia em termos de História do Brasil, pois enquanto grandes clássicos, como Casa Grande \& Senzala de Gilberto Freyre, defendem a constituição de um Brasil mulato e mestiço, para Bento tal argumento não correspondia a formação social e cultural sulista. ${ }^{56}$

Esse passado-presente, ou seja, o espaço de experiência brasileiro, era definido como indesejado para o futuro. A população negra era localizada fora do Paraná, era "carioca" e viveria em um local com topografia montanhosa ("perambeira”), era constituída assim como um avesso das concepçóes de futuro presentes nos discursos de Rocha Neto e dos repórteres, que projetavam a imagem de um trigal loiro e plano. Para compreender essa percepção de historicidade, lembramos as reflexóes de Reinhard Koselleck:

Com isso chego a minha tese: experiência e expectativa são duas categorias adequadas para nos ocuparmos com o tempo histórico, pois elas entrelaçam passado e futuro. São adequadas também para se tentar descobrir o tempo histórico, pois, enriquecidas em seu conteúdo, elas dirigem as ações concretas no movimento social e político. ${ }^{57}$

Podemos afirmar, a partir dos discursos apresentados, que os autores em questão estão não só construindo uma narrativa fundante para o Paraná, mas sim uma historicidade para

\footnotetext{
${ }^{56}$ CORDOVA Maria Julieta W. O discurso regional autorizado de formação social e histórica paranaense, op. cit., p. 6. Grifo da autora.

${ }^{57}$ KOSELLECK. Reinhardt. Futuro passado: contribuição à semântica dos tempos históricos. Rio de Janeiro: Contraponto/PUC-Rio, 2006. p. 308.
} 
o Brasil, pois que o estado não seria um resumo do Brasil do presente, visto como atrasado, pobre e negro, mas sim, um horizonte de expectativa para um Brasil do futuro. Porém, tal ideia de progresso excluía as populações compreendidas como representantes de um passado-presente a ser superado.

$\mathrm{Na}$ construção desse futuro técnico e branco desejado pelos articulistas, encontrava-se uma figura limítrofe no mundo rural por eles abordado: o caboclo. Tal personagem constitui-se como um momento privilegiado para a análise das representaçóes discursivas sobre a população brasileira no período. Márcia Naxara apontou a passagem do século XIX para o XX como o momento em que surgiram diversas concepçôes sobre a constituição do povo brasileiro dentro de uma perspectiva evolucionista, as quais traziam a ideia de uma humanidade em uma marcha em direção ao progresso, para a qual os nacionais, por motivos variados, não estariam aptos. ${ }^{58}$ Tais formulaçóes parecem ter se cristalizado durante a primeira metade do século XX e as encontramos de forma refigurada nos discursos de Bento Munhoz.

Será necessário um último olhar atento para tal discursividade com vistas a compreender como diferentes projetos de futuro estavam mesclados a uma percepçáo da historicidade do rural no Paraná. O personagem caboclo apresentava-se, assim, como uma figura limítrofe na representação da brasilidade - nem branco, nem negro, nem indígena. De difícil classificação, ele expunha um Brasil rural miscigenado; era a figura dos sertôes, o decaído ou doente Jeca Tatu. ${ }^{59}$ Mas, para Bento Munhoz da Rocha, ele existia também dentro de cada um de nós, brasileiros. Daí referir-se a um "caboclismo nosso", seguindo as palavras do político: “o caboclismo nosso de cada dia, acha bonito o que está escrito em inglês, [...] advinha a sabedoria de vagas técnicas agronômicas” e compóem-se em oposição a uma “[...] colonização racional, como se iniciou em Guarapuava, onde grande colônia de raça e cultura alemã cultiva trigo em campos nativos que permitem mecanização". ${ }^{60}$ Tal caboclismo nacional pode ser visto também quando o autor analisa a mudança na cultura do café:

Há uma década soaria como absurdo aconselhar a um lavrador de café do Paraná a adubação da terra. O lavrador sabia que quando a terra se esgotasse iria em frente como um andarilho. Era um de seus defeitos psicológicos, análogo ao fronteirismo norte-americano em que a mudança, o deslocamento, a busca de novas paisagens, resolvia todos os problemas. ${ }^{61}$

\footnotetext{
58 “[...] momento de lenta e contraditória gestação das representaçốes que levariam à cristalização de uma imagem instituidora do brasileiro enquanto indolente, vadio, que permaneceu como uma pecha ou mito, generalizando-se e abrangendo, de certa forma, o povo brasileiro, dando-lhe como características básicas a preguiça, o conformismo, e a ideia de inadequação à civilização em marcha.” NAXARA, Márcia R. C. Estrangeiro na sua própria terra: representaçóes do brasileiro 1870/1920. São Paulo: Annablume, 1998. p. 19.

${ }^{59}$ NAXARA, Márcia R. C. Estrangeiro na sua própria terra, op. cit. p. 17.

${ }^{60}$ ROCHA NETO, Bento Munhoz da. O Paraná: ensaios, op. cit, p. 59-60.

${ }^{61}$ Ibidem, p. 61.
} 
Na passagem, o autor compara o lavrador nacional com a noção de fronteira presente na historiografia norte-americana, assim "[...] é possível perceber continuidades discursivas para problemas de território e nação que constituíram, nas suas especificidades, relaçóes de poder que delimitaram suas fronteiras" ${ }^{62} \mathrm{O}$ próprio percurso desses conceitos de fronteira embasou projetos políticos de expansão de estados em distintos tempos e espaços na América. Uma analogia baseada no movimento populacional, não na sua qualidade.

O fragmento de Rocha Neto também aponta para a permanência da ideia de destino acerca dos agricultores nacionais, agora denominados caboclos. Como podemos ver, não se trata de um destino que os conduziria para um futuro/fortuna, mas, ao contrário, os aprisiona em um pretérito/infortúnio. Sua sina é representada pelo deslocamento constante para o interior em busca de novas terras, como primeiro elemento desbravador, mas, para quem, paradoxalmente, raramente os títulos de pioneiro, ou elemento civilizador, são atribuídos. ${ }^{63}$ Jogados no passado, apesar de serem componentes daquele presente, os agricultores nacionais/caboclos também estavam sob o estigma do atraso. Ao final, o autor comemora o que entende como uma diminuição do que ele mesmo identificava como um "caboclismo" e afirma: "Para felicidade nossa, essa atitude está desaparecendo" ${ }^{64}$ No horizonte de expectativa ali projetado, não haveria lugar para as figuras limítrofes, como caboclos e caboclismos, vistos como remanescentes de um passado agora indesejado.

O presente da década de 50 do século passado era, para Rocha Neto, um tempo de realizaçóes, de transformaçóes, pois que os efeitos das imigraçóes europeias já estavam sendo vistos na população paranaense e um novo brasileiro surgia, a saber: "Como os caboclos loiros de Guarapuava, de origem nórdica, abrasileirados, pela convivência nacional e total predominância de nossa cultura". ${ }^{65} \mathrm{E}$, nesse sentido, o político diminuía o papel dos outros povos na composição da população do Paraná. Os indígenas e os negros eram percebidos como tendo uma contribuição "[...] minguada, pois a ausência de cultura extensiva e intensiva nos tempos de colônia - a pecuária foi nessa época a grande atividade - não exigiu a importação do braço escravo, na mesma intensidade que nas zonas onde se estabeleceu, por primeiro, o eixo da economia brasileira". ${ }^{66} \mathrm{O}$ adjetivo "minguar", utilizado para se referir às diversas naçóes indígenas e populaçóes descendentes de pessoas escravizadas, passava uma obliteração de vidas, as quais, naquele momento, eram exterminadas no chamado norte novíssimo do Paraná e na grilagem das terras pertencentes à fazenda Invernada Paiol da

\footnotetext{
${ }^{62}$ FIÚZA, Wagner H. N.; OLINTO, Beatriz A. Fronteiras em movimento: o Oeste nos Estados Unidos e no Brasil. RELACULT - Revista Latino-Americana de Estudos em Cultura e Sociedade. v. 3, ed. especial, dez. 2017 (artigo n. 530). Disponível em: relacult.claerc.org. Acesso em: 16 abr. 2018.

${ }^{63}$ OLINTO, Beatriz A.; STEIN, Marcos N. As propriedades da diferença: nacionais, colonos e grileiros (Guarapuava 1920-1930). In: MOTTA, Marcia M.; OLINTO, Beatriz A.; OLIVEIRA, Oséias (orgs.) História agrária: propriedade e conflito. Guarapuava: Unicentro, 2009. p. 301.

${ }^{64}$ ROCHA NETO, Bento Munhoz da. O Paraná: ensaios, op. cit., p. 61.

${ }^{65}$ Ibidem, p. 146.

${ }^{66}$ Ibidem, p. 80-81.
} 
Telha, em Guarapuava. ${ }^{67}$ Mas o massacre não é visto como tal, ele aparece escamoteado na naturalização da marcha do progresso, que escolheu quem iria sobreviver e prosperar:

É pela cultura luso-brasileira que estamos construindo no sul o mesmo Brasil de sempre, o mesmo Brasil talhado para sobreviver, um Brasil mais branco, loiro, em que são sensíveis os traços culturais europeus não portugueses, um Brasil que se diversifica, que se distingue com seus aspectos próprios, mas que é o mesmo Brasil, [...]. ${ }^{68}$

Como já foi dito, os nacionais pobres, os indígenas e os negros eram vistos como um passado no presente, o futuro era loiro e europeu, mesmo que "abrasileirado". Lembrando Woodward: "Todas as significaçóes que produzem significados envolvem relaçóes de poder, incluindo o poder de definir quem é incluído e quem é excluído". ${ }^{9}$ Nesse caso, a inclusão era uma questão de sobrevivência e direito a um futuro.

Delimitavam-se sujeitos, seus lugares e suas atividades, entre o dito e o silenciado, vidas humanas e seus direitos eram percebidos ou apagados. Os papéis sociais eram idealizados em um teatro perspectivo, um horizonte de desejo futuro utilitarista, branco e ordeiro, como pode ser compreendido mais uma vez abaixo:

É o sertanejo, queimando a coivara para plantar roça. É o colono de todos os climas e de todas as latitudes, egresso de terras cansadas de séculos, esterilizadas pelos conflitos da questão social; morigerado colono, que prospera na floração da gleba. É o ervateiro podando o erval dourado. É o pouso silencioso das carroças de quinze cavalos ao longo das estradas. É a cadência uniforme das serrarias e dos engenhos. É o oceano verde dos cafezais e a fulguração nova de searas. São as criancinhas loiras buscando escola, em limpas e luminosas manhãs de gelo. ${ }^{70}$

\footnotetext{
${ }^{67} \mathrm{O}$ imóvel denominado Invernada Paiol da Telha localizava-se no atual município de Pinhão. A área foi deixada, em 1860, em testamento pela proprietária, Dona Balbina Siqueira, para os ex-escravos. Posteriormente, em 1875, grande parte das terras teriam sido usurpadas por Pedro Lustoza de Siqueira, grande proprietário de terras da região. A fase final dessa expropriação ocorrerá durante a ditadura militar, culminando, em 1975, quando João Pinto Ribeiro, então delegado de Pinhão, expropria violentamente os remanescentes de escravos que viviam na área que, então, foi adquirida pela cooperativa Agrária, formada pelos suábios do Danúbio. No início da década de 1990, um grupo de famílias de descendentes dos escravos reocupou a área, seguindo-se um processo marcado por diversos conflitos. Para mais informaçôes, ver: HARTUNG, Miriam F. O sangue e o espirito dos antepassados: escravidão, herança e expropriação no grupo negro Invernada Paiol da Telha-PR. Florianópolis: NUER/UFSC, 2004 e STEIN, Marcos N; OLINTO, Beatriz A.; KRAMER, Méri F. Um Paraná esquecido: deslocamentos, memórias e conflitos em Guarapuava. In: COSTA, Hilton; PEGORARO, Jonas; STANCZYK FILHO, Milton (orgs.). Paraná pelo caminho: histórias, trajetórias e perspectivas. Volume III - Movimentos. Curitiba: Máquina de Escrever, 2017. p. 70-99.

${ }^{68}$ ROCHA NETO, Bento Munhoz da. O Paraná: ensaios, op. cit., p. 83.

${ }^{69}$ WOODWARD, Kathryn. Identidade e diferença: uma introdução teórica e conceitual. In: SILVA, Tomaz T. da. (org.) Identidade e diferença: a perspectiva dos estudos culturais. Traduçóes de Tomaz Tadeu da Silva. Petrópolis, RJ: Vozes, 2000. p. 18.

${ }^{70}$ ROCHA NETO, Bento Munhoz da. O Paraná: ensaios, op. cit., p. 48.
} 
Um horizonte ordenado em uma lógica produtiva da terra capitalista, na qual a natureza era compreendida ora como recurso, ora como obstáculo, ou seja, como algo a ser utilizado, um recurso com propriedade definida. A grilagem, vista como uma exceção, continuava como dinâmica de reocupação de terras. As populaçôes locais e seus conhecimentos eram apagados ou desqualificados em um horizonte constituído por palavras de força simbólica como progresso, futuro e trabalho. O futuro - representado pelas crianças - pertenceria aos loiros, o fenótipo apresentado para a nova geração. Sob o som das "serrarias e engenhos", eram silenciados outros futuros possíveis e outras formas de estar no mundo, campos de experiência vistos como atrasados ou superados. Ao narrar um Paraná e construir um horizonte de expectativa para o estado, delimitava-se também um futuro para o Brasil, pois, como lembra Foucault: "O discurso nada mais é do que a reverberação de uma verdade nascendo diante de seus próprios olhos" ${ }^{71}$ Verdades que, mesmo de emergência recente, parecem perdurar como o horizonte do mundo rural brasileiro.

\section{Considerações finais}

Criar uma identidade para a população paranaense envolvia criar um passado, uma história e uma temporalidade progressiva. A problematização das historicidades desenhadas por entre discursos identitários e suas narrativas é uma forma eficaz de perceber o seu enredo e de compreender as relaçóes com projetos que, como vimos, previam um futuro somente para alguns grupos humanos. A expropriação do acesso à terra no Paraná, especialmente em meados do século XX, não foi uma dinâmica inconsciente, inerente à modernização agrícola, circunscritas somente ao campo econômico. Ao contrário, ambas foram projetos de futuro desejados e fundamentados em concepçóes de história como um processo progressivo, irreversível e excludente, pois, como lembrava Abramovay: "[...] uma verdadeira história agrária não se pode limitar à história econômica: os costumes, as tradições étnicas e nacionais, a cultura de forma geral têm aí um papel de destaque". ${ }^{72}$

Narrar o passado implica construir interpretaçóes sobre o pretérito com vistas aos interesses do presente e às suas projeçôes de futuro. E esse futuro, como vimos, não era para todos. No caso dos discursos de Rocha Neto e dos repórteres que o acompanharam na viagem pelo interior do Paraná, em 1952, trata-se do estabelecimento, por meio da linguagem, de um quadro em que os lugares e os papéis eram definidos em uma sociedade hierarquizada. Inclusive, governar não era uma atividade para muitos, pois que "À elite, isto é, à minoria, cumpre a missão de dirigir. Está na essência da direção e do governo a noção de minoria.

\footnotetext{
${ }^{71}$ FOUCAULT, Michel. A ordem do discurso. 3 ed. São Paulo: Loyola, 1996. p. 49.

${ }^{72}$ ABRAMOVAY, Ricardo. Transformação da vida camponesa: o sudoeste paranaense. Dissertação (Mestrado em Ciências Sociais). São Paulo: USP, 1981. p. 12.
} 
Governo é minoria dirigindo; minoria, elite no comando". ${ }^{73}$ Essa elite pensava um lugar, delimitava um estado, sua história, seus personagens e sua hierarquia.

Nesse sentido, o Paraná foi construído, nesses discursos, como uma região com suas especificidades, um geografismo que o definia e o naturalizava. Também se estava a construir uma identidade relacional do estado com o Brasil. O Paraná era apresentado não só como parte do país, tratava-se também de um modelo de desenvolvimento agrário e populacional para a nação, narrativas que, ao mesmo tempo, historicizavam diferenças e projetavam o futuro para uma naçăo "abrasileirada" ao seu feitio.

\section{Referências}

ABRAMOVAY, Ricardo. Transformaçâo da vida camponesa: o sudoeste paranaense. Dissertação (Mestrado em Ciências Sociais). São Paulo: USP, 1981.

ABRAMOVAY, Ricardo. Funçôes e medidas da ruralidade no desenvolvimento contemporâneo. Rio de Janeiro: IPEA, 2000. Disponível em: http://ipea.gov.br/agencia/images/stories/ PDFs/TDs/td_0702.pdf. Acesso em: 15 nov. 2018.

BAHLS, Aparecida Vaz da S. A busca de valores identitários: a memória histórica paranaense. Tese (Doutorado em História) Curitiba: UFPR, 2007.

BALHANA, Altiva P.; MACHADO Paulo P. (orgs.). Campos gerais: estruturas agrárias. Curitiba: UFPR, 1968.

BOURDIEU, Pierre. O poder simbólico. Rio de Janeiro: Bertrand, 1989.

BRAGA, Rubem; D'HORTA, Arnaldo. Dois repórteres no Paraná. 2 ed. Curitiba: Imprensa Oficial do Paraná, 2001.

CORDOVA, Maria Julieta W. O discurso regional autorizado de formação social e histórica paranaense. Sociologia \& Política. I Seminário Nacional de Sociologia e Política. UFPR: 2009. Disponível em: http://humanas.ufpr.br/site/evento/SociologiaPolitica/anais/gt6.htm. ELFES, Albert. Campos gerais: estudo da colonização. Curitiba: Incra, 1973.

FOUCAULT, Michel. A ordem do discurso. 3 ed. São Paulo: Loyola, 1996.

FROTSCHER, Méri F; STEIN, Marcos N.; OLINTO, Beatriz. A. Memória, ressentimento e politização do trauma: narrativas da II Guerra Mundial (Suábios do Danúbio de Entre Rios, Guarapuava - PR). Revista Tempo, Niterói, v. 20, p. 1-26, 2014.

FROTSCHER, Méri F.; STEIN, Marcos N.; OLINTO, Beatriz A. Eles também não tinham nada: narrativas orais de deslocamentos e encontros identitários em Entre Rios (Guarapuava - PR). Diálogos, Maringá, v. 18, n. 3, p. 1.039-1.067, set./dez. 2014.

\footnotetext{
${ }^{73}$ ROCHA NETO, Bento Munhoz da. O Paraná: ensaios, op. cit., p. 113.
} 
GONÇALVES, José Henrique R. A “mística do pioneirismo”, antídoto contra o socialismo: Bento Munhoz da Rocha Neto, a reforma agrária e o Norte do Paraná dos anos 50 e 60. Revista História Regional, v. 2, n. 1, p. 145-171. Ponta Grossa: UEPG, 1997.

HARTOG, François. Regimes de historicidade: presentismo e experiências do tempo. Belo Horizonte: Autêntica, 2013.

HARTUNG, Miriam F. O sangue e o espírito dos antepassados: escravidão, herança e expropriação no grupo negro Invernada Paiol da Telha - PR. Florianópolis: NUER/UFSC, 2004.

KOSELLECK, Reinhart. Futuro passado: contribuição à semântica dos tempos históricos. Rio de Janeiro: Contraponto/ PUC-Rio, 2006.

LACOSTE, Yves. A geografia: isso serve, em primeiro lugar, para fazer a guerra. Disponível em: http://www.sabotagem.cjb.net. Acesso em: 13 nov. 2018.

MELO, Mariani Carolina de S. A crônica vai à guerra: Rubem Braga e os escritos do front. Dissertação (Mestrado em Teoria Literária). Uberlândia: UFU, 2016.

MOTTA, Márcia M. M. A grilagem como legado (2001).

Disponível em:

http://www.direito.mppr.mp.br/arquivos/File/Politica_Agraria/7MottaAGrilagemcomoLeg ado.pdf. Acesso: 04 dez. 2017.

MOTTA, Márcia M. M. (org.) Dicionário da Terra. Rio de Janeiro: Civilização Brasileira, 2005.

MOTTA, Márcia M. M. O rural à la gauche: campesinato e latifúndio nas interpretaçóes de esquerda (1955-1996). Niterói: UFF, 2014.

NAXARA, Márcia R. C. Estrangeiro na sua própria terra: representaçóes do brasileiro 1870/1920. São Paulo: Annablume, 1998.

OLINTO, Beatriz A.; STEIN, Marcos N. As propriedades da diferença: nacionais, colonos e grileiros (Guarapuava 1920-1930). In: MOTTA, Márcia M.; OLINTO, Beatriz A.; OLIVEIRA, Oséias (orgs.) História agrária: propriedade e conflito. Guarapuava: Unicentro, 2009. p. 231-246.

OLIVEIRA, Semi C. de. Ciclos econômicos da erva-mate e do café. In: SCORTEGAGNA, Adalberto et al. (org.) Paraná Espaço e Memória: diversos olhares histórico-geográficos. Curitiba: Bagozzi, 2005. p. 204-227.

PRIORI, Angelo et al. História do Paraná: séculos XIX e XX [online]. Maringá: Eduem, 2012. A revolta camponesa de Porecatu. p. 129-141. Disponível em: http://books.scielo.org/ id/k4vrh/pdf/priori-9788576285878-11.pdf. Acesso em: 13 nov. 2018.

PRIORI, Angelo et al. A Guerra de Porecatu. Revista Diálogos. UEM, v. 14, n. 2, p. 367$379,2010$. 
RICEUR, Paul. A memória, a história, o esquecimento. Campinas: Unicamp, 2007.

ROCHA NETO, Bento Munhoz da. Discursos e conferências 1951-1955. Curitiba: Imprensa Oficial. s/d.

ROCHA NETO, Bento Munhoz da. O Paraná: ensaios. Curitiba: Coleção Farol do Saber, 1995.

ROCHA NETO, Bento Munhoz da. Mensagem apresentada à Assembleia do estado pelo senhor governador do Paraná. In: Paraná, Câmara de Expansão Economica. $1^{\circ}$ Centenário da Emancipação Política do Paraná (1853-1953). Porto Alegre: Clarin Cemrpresa de Publicidade/ Livraria do Globo, 1953.

STEIN, Marcos N. O oitavo dia: produção de sentidos identitários na Colônia Entre Rios PR (segunda metade do século XX). Guarapuava: Unicentro, 2011.

STEIN, Marcos N; OLINTO, Beatriz A.; KRAMER, Méri F. Um Paraná esquecido: deslocamentos, memórias e conflitos em Guarapuava. In: COSTA, Hilton; PEGORARO, Jonas; STANCZYK FILHO, Milton (org.). Paraná pelo caminho: histórias, trajetórias e perspectivas. v. III - Movimentos. Curitiba: Máquina de Escrever, 2017. p. 70-99.

WACHOWICZ, Ruy C. Paraná, Sudoeste: ocupação e colonização. Curitiba: Lítero-Técnica, 1985.

WOODWARD, Kathryn. Identidade e diferença: uma introdução teórica e conceitual. In: SILVA, Tomaz T. da (org.). Identidade e diferença: a perspectiva dos estudos culturais. Traduçôes de Tomaz Tadeu da Silva. Petrópolis, RJ: Vozes, 2000. p. 7-72. 